\title{
Transformações urbanas em São Paulo
}

\author{
MARIA PATRÍCIA RUIVO I e JOSÉ FRANCISCO II
}

\section{Introdução e justificativa}

$\mathrm{D}$ EPOIS de anos de debates e propostas para reversão do processo de decréscimo populacional, abandono e degradação do patrimônio edificado no centro de São Paulo, entre os anos 2000 e 2010 houve uma alteração no fluxo migratório dos principais distritos municipais da região central. Durante a primeira década do século XXI, período que coincide com a aprovação do Estatuto da Cidade (Lei n.10.257) em 2001 e do Plano Diretor Estratégico do Município (PDE), Lei n.13.430/02 (em vigor de setembro de 2002 a julho de 2014), a região central passou a atrair novos moradores.

De acordo com os dados do Censo populacional divulgados pelo Instituto Brasileiro de Geografia e Estatística (IBGE) em 2010, todos os distritos municipais da Subprefeitura da Sé passaram a registrar taxas de crescimento positivas, superiores à taxa de crescimento observada no município durante o mesmo período. Pela primeira vez em décadas a região passa a atrair novos moradores, totalizando 57.192 novos habitantes. Apesar disso, a população da região central continua menor do que a registrada em $1980 .{ }^{1}$

Depois da aprovação do PDE em 2002 e da implementação de instrumentos urbanísticos de incentivo ao uso habitacional em áreas consolidadas da cidade, a região central de São Paulo voltou a ser objeto de interesse do mercado imobiliário. Mas a aplicação seletiva desses mesmos instrumentos acarretou uma série de contradições na ocupação do território. Os principais instrumentos disponibilizados para garantir a função social da propriedade e estímulo à recuperação dos edifícios existentes não tiveram uma aplicação efetiva, enquanto os instrumentos de estímulo ao adensamento e à construção de novos edifícios foram largamente utilizados. Também tiveram resultados tímidos os instrumentos que deveriam garantir a permanência de populações de menor poder aquisitivo na região central, bem como o controle da especulação imobiliária e valorização dos imóveis (Ruivo; Castro, 2014).

Durante o período houve uma intensificação na construção de novos edifícios nos principais distritos municipais da região central, impulsionados pela disponibilidade de Outorga Onerosa do Direito de Construir, enquanto parte do patrimônio edificado continuou subutilizado, descumprindo sua função social. O estímulo ao adensamento de regiões consolidadas da cidade bem servidas de infraestrutura urbana, especialmente áreas próximas a corredores de transporte 
coletivo de massa, acarretou um aumento no valor de imóveis e terrenos. Sem ações efetivas capazes de garantir a manutenção de populações de menor poder aquisitivo na região central, o aumento no valor dos imóveis acabou dificultando o acesso e a permanência desses moradores, efeito contrário ao pretendido inicialmente pelo PDE. Sem contar o fato de que adensar nesse caso específico não significa necessariamente construir novos edifícios. Se compararmos a densidade habitacional da Subprefeitura da Sé em 2010 (164.54 hab/ha) com a densidade na década de $1980(200,83 \mathrm{hab} / \mathrm{ha}),{ }^{2}$ é possível perceber que ainda hoje há um potencial de adensamento subutilizado na região, que deveria ter sido estimulado prioritariamente antes do incentivo ao lançamento de novos empreendimentos.

Depois de longo período de abandono e perda de investimentos tanto públicos como privados, a partir dos anos 2000 parte da região central de São Paulo passa novamente a reunir elementos atrativos ao mercado imobiliário. Entre esses elementos podem-se destacar: localização privilegiada, baixo valor dos terrenos e imóveis (comparados com seu potencial de valorização - potential ground rent $t^{3}$ ), aumento na oferta de empregos na região e disponibilidade de crédito para construção e aquisição dos imóveis. A união desses fatores resultou em diminuição dos riscos e criou condições favoráveis para a volta de investimentos à área central. Sem a efetividade dos instrumentos de planejamento urbano capazes de priorizar a recuperação do patrimônio edificado e inibir em um primeiro momento a construção de novos edifícios, regiões bem localizadas com grande potencial de valorização passaram por processos de transformação espacial, dando início a um intenso ciclo de desconstrução espacial e ressignificação do espaço urbano.

Segundo Francisco (2002), qualquer alteração do espaço, seja natural, seja transformado, implica necessariamente uma alteração do espaço existente. Esse processo de transformação, quando antrópico, pode ser denominado desconstrução espacial. Partindo desse princípio e utilizando o conceito de desconstrução espacial como instrumento de análise das transformações urbanas do período, a seguir veremos com mais detalhes como a conjunção desses fatores afetou um dos distritos municipais da Subprefeitura da Sé, a Bela Vista, e quais as características do espaço produzido no período, por meio do exemplo da rua Paim.

\section{Objetivos, material e método}

O presente artigo tem por objetivo investigar as transformações espaciais da área central de São Paulo entre os anos 2000 e 2010, como reflexo não apenas das ações de agentes privados, mas também das diretrizes definidas pelo PDE e da utilização (ou não) dos principais instrumentos urbanísticos disponíveis para controle da função social da propriedade.

Mediante uma revisão bibliográfica e aprofundamento teórico referentes ao desenvolvimento urbano da cidade de São Paulo, além de um estudo de caso sobre as transformações urbanas sofridas pela rua Paim (bairro Bela Vista) ao longo da década, pretende-se demonstrar que, apesar dos avanços presentes no Estatuto da Cidade e no PDE, a lógica de ocupação do espaço urbano, respon- 
sável pela produção de espaços segregados e excludentes, permaneceu inalterada e seguiu os mesmos padrões de ocupação que nortearam o crescimento da cidade desde meados do século XIX.

O estudo de caso da pesquisa foi escolhido em razão de sua capacidade de representação das principais características da produção do mercado imobiliário no período, não apenas físicas e arquitetônicas, mas fundamentalmente de suas estratégias de ocupação e transformação do espaço existente. Mais do que um recurso exploratório, o estudo de caso foi utilizado como estratégia para entender a dinâmica de ocupação do espaço no período em questão, contribuindo para a compreensão dos fenômenos individuais, organizacionais, sociais e políticos envolvidos (Yin, 2001). A escolha da rua Paim, localizada no bairro Bela Vista, tem como objetivo recuperar a totalidade do processo de produção do espaço, buscando compreender não apenas as transformações físicas, mas também os aspectos históricos, culturais e sociais envolvidos. As principais fontes documentais utilizadas pela pesquisa foram: censos demográficos do IBGE; dados disponibilizados pela Prefeitura Municipal de São Paulo (PMSP); Empresa Brasileira de Estudos de Patrimônio (Embraesp); além da coleta de dados e observações em campo.

\section{Desconstrução e produção do espaço urbano}

Desde a promulgação da Lei de Terras no ano 1850, a maioria dos processos de desenvolvimento urbano e desconstrução espacial na cidade de São Paulo esteve subordinada à lógica de acumulação capitalista. O crescimento da cidade foi orientado segundo interesses econômicos imediatos, negligenciando os impactos negativos decorrentes das transformações urbanas, tanto com relação ao passado e à natureza que estava sendo alterada, mas principalmente com relação ao futuro.

O processo de diminuição populacional e fuga de investimentos na região central a partir da segunda metade do século XX, bem como o crescimento desmesurado da mancha urbana em direção a áreas periféricas não foram fenômenos isolados na capital paulista. De acordo com Bonduki (2010), as principais metrópoles brasileiras passaram por um processo gravíssimo de perda de população nas áreas urbanas mais bem servidas por infraestrutura e emprego, além de um crescimento acelerado de regiões periféricas e ocupação indevida de áreas de proteção ambiental.

As dinâmicas relacionadas ao desenvolvimento urbano quando submetidas ao modo de produção capitalista estão sujeitas à sua lógica de acumulação, que por sua vez se insere em um mercado altamente globalizado e dinâmico, em permanente busca por novos nichos de atuação (Harvey, 2005). O processo de abandono e a perda de investimentos da área central de São Paulo, iniciado na década de 1950 e aprofundado a partir dos anos 1980, para áreas de maior rentabilidade, obedece a essa lógica, e pode até certo ponto ser considerado previsível. Tanto que processos similares ocorreram não apenas nas principais capitais do Brasil, mas em importantes cidades de diversos países da Europa e América. 
Os processos de desconstrução espacial da cidade de São Paulo, desde a segunda metade do século XIX, estiveram na maioria das vezes subordinados a interesses privados, e as formas de ocupação do território refletem isso. Mas embora esses mesmos interesses tenham tido um papel decisivo na orientação do crescimento da cidade, não se pode dizer que não houve resistência para conter a especulação imobiliária e orientar o crescimento. No início da década de 1960 há uma intensificação no debate político acerca dos principais problemas estruturais das cidades brasileiras. Durante o governo João Goulart inicia-se uma série de discussões sobre questões como a reforma agrária, educação e o desenvolvimento nacional. Um marco desse processo foi a realização do Seminário de Habitação e Reforma Urbana (SHRU), realizado em 1963 e promovido pelo Instituto de Arquitetos do Brasil, com apoio do governo federal por meio do Instituto de Aposentadoria e Pensão dos Servidores do Estado (Ipase). Esse seminário resultou em várias propostas importantes para uma nova política urbana e habitacional, que acabaram suspensas com o golpe militar de 1964. Segundo Bonduki e Koury (2010), embora o golpe tenha interrompido as perspectivas políticas e reformistas introduzidas pelo SHRU, seus desdobramentos foram importantes. Parte das propostas do seminário foi apropriada pelo regime militar, fato que influenciou a criação do Banco Nacional de Habitação (BNH) e do Serviço Federal de Habitação e Urbanismo (Serfhau). E as propostas mais progressistas defendidas durante o evento, contrárias à posição do regime, ficaram latentes e foram retomadas décadas depois, influenciando os movimentos pela reforma urbana na Constituinte de 1988, além da luta durante a década de 1990 pela aprovação do Estatuto da Cidade.

A partir dos anos 1980 há uma intensificação nas pressões pela reforma urbana por movimentos sociais, estudantis e sindicais, dando origem ao Movimento Nacional pela Reforma Urbana (MNRU). Um dos marcos importantes dessa trajetória de luta pelo direito à cidade foi a inclusão dos artigos 182 e 183 na Constituição Federal em 1988, que tratam da política urbana e incorporam a noção de função social da propriedade no corpo da lei. A partir desse momento o direito à propriedade deixa de ser absoluto, e a existência de imóveis ociosos que não cumprem sua função social passa a ser passível de sanções. Mas apesar do avanço, foram necessários outros treze anos de debates para regulamentar o texto da política urbana, e apenas no ano de 2001 é aprovada a Lei Federal n.10.257/2001, também conhecida como Estatuto da Cidade. Com o objetivo de regular o cumprimento da função social da propriedade urbana, o Estatuto fornece os instrumentos urbanísticos necessários para uma ação concreta sobre as regras de produção do espaço, planejamento e gestão urbana participativos. Além disso, estabelece limites para a propriedade do solo apresentando as condições para o cumprimento da função social da propriedade. A implementação do Estatuto da Cidade torna possível e atuação sobre o mercado de terras urbanas, controlando e diminuindo as possibilidades de especulação imobiliária. Segundo Maricato (2010), o Estatuto reforça a orientação autônoma e descentralizadora 
assegurada aos municípios pela Constituição brasileira, que por meio do Plano Diretor ou legislação complementar definem quais propriedades são passíveis de sanções de instrumentos urbanísticos. De acordo com a autora, dependendo da correlação de forças no município, a lei pode ter aplicação efetiva ou não.

$\mathrm{O}$ que se pretende investigar no trabalho é justamente o alcance do Estatuto da Cidade como indutor de uma mudança de paradigma no desenvolvimento urbano da cidade de São Paulo, cerca de dez anos após sua aprovação. Como se deu o processo de desconstrução espacial da área central de São Paulo durante o período, e quais as características do espaço produzido?

\section{O processo de desconstrução espacial da rua Paim, bairro Bela Vista}

Depois de um longo período de abandono, intensificado a partir dos anos 1980, a rua Paim (Figura 1), localizada no bairro Bela Vista, tornou-se objeto de desejo de incorporadores e construtores na primeira década do século XXI.

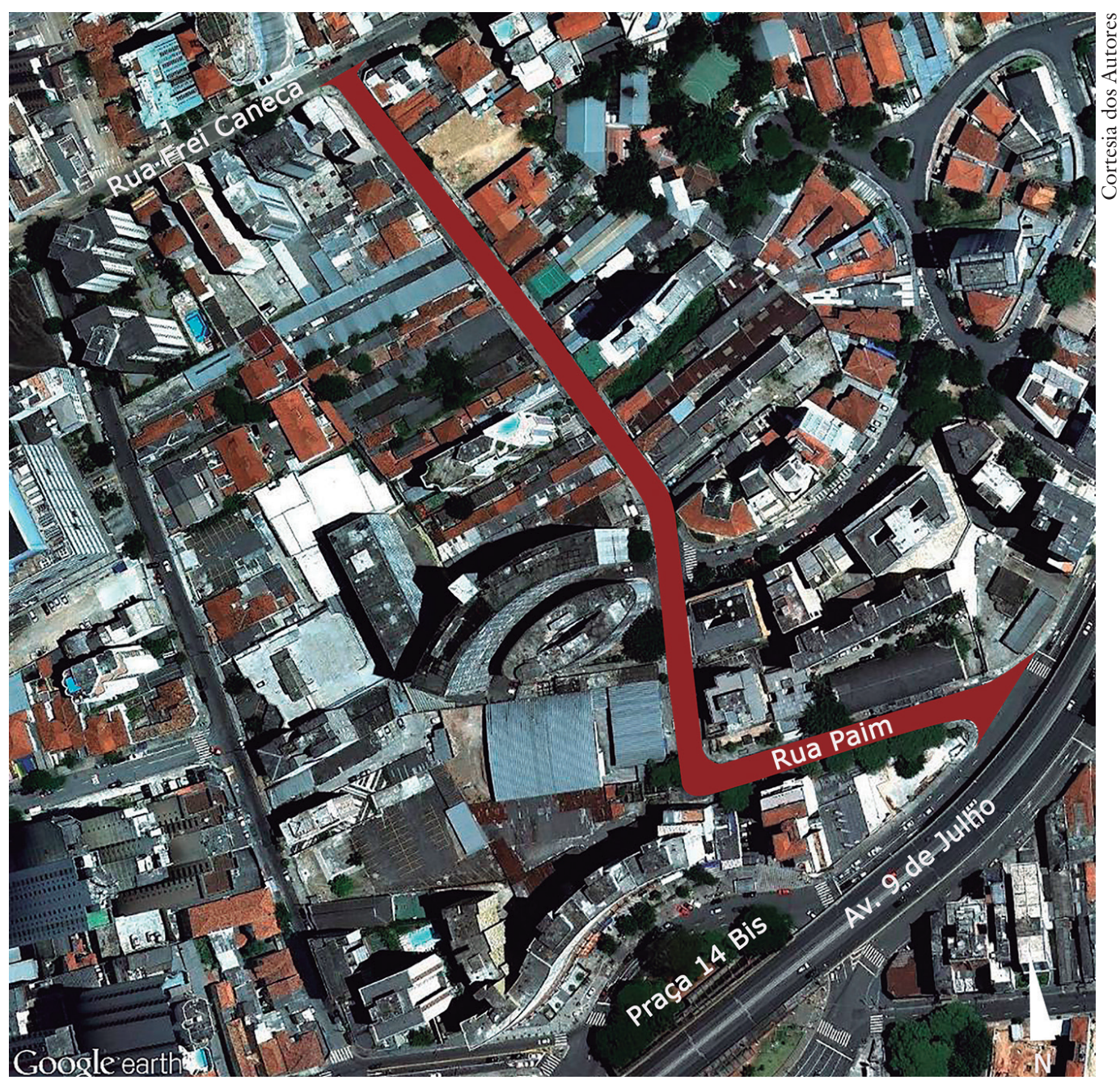

Figura 1 - Foto aérea da rua Paim (2008). ${ }^{4}$ 
Nesse momento há uma reunião de fatores-chave capazes de diminuir os riscos e aumentar o retorno financeiro de investir na região. Entre esses fatores podemos destacar a localização privilegiada; o aumento da oferta de empregos, não apenas na Bela Vista, mas na região central como um todo; o anúncio do Plano de expansão do Metrô (linha 6 - laranja) com construção da estação 14 Bis nas proximidades; a disponibilidade de imóveis com baixo valor de mercado em terrenos com alto potencial construtivo, além da farta disponibilidade de crédito e linhas de financiamento tanto para a construção como para aquisição de imóveis.

O recorte do mapa cadastral da região (Figura 2) mostra a ocupação da rua no início da década, com grande disponibilidade de lotes estreitos e profundos, ocupados em sua maioria por construções baixas em precário estado de conservação.

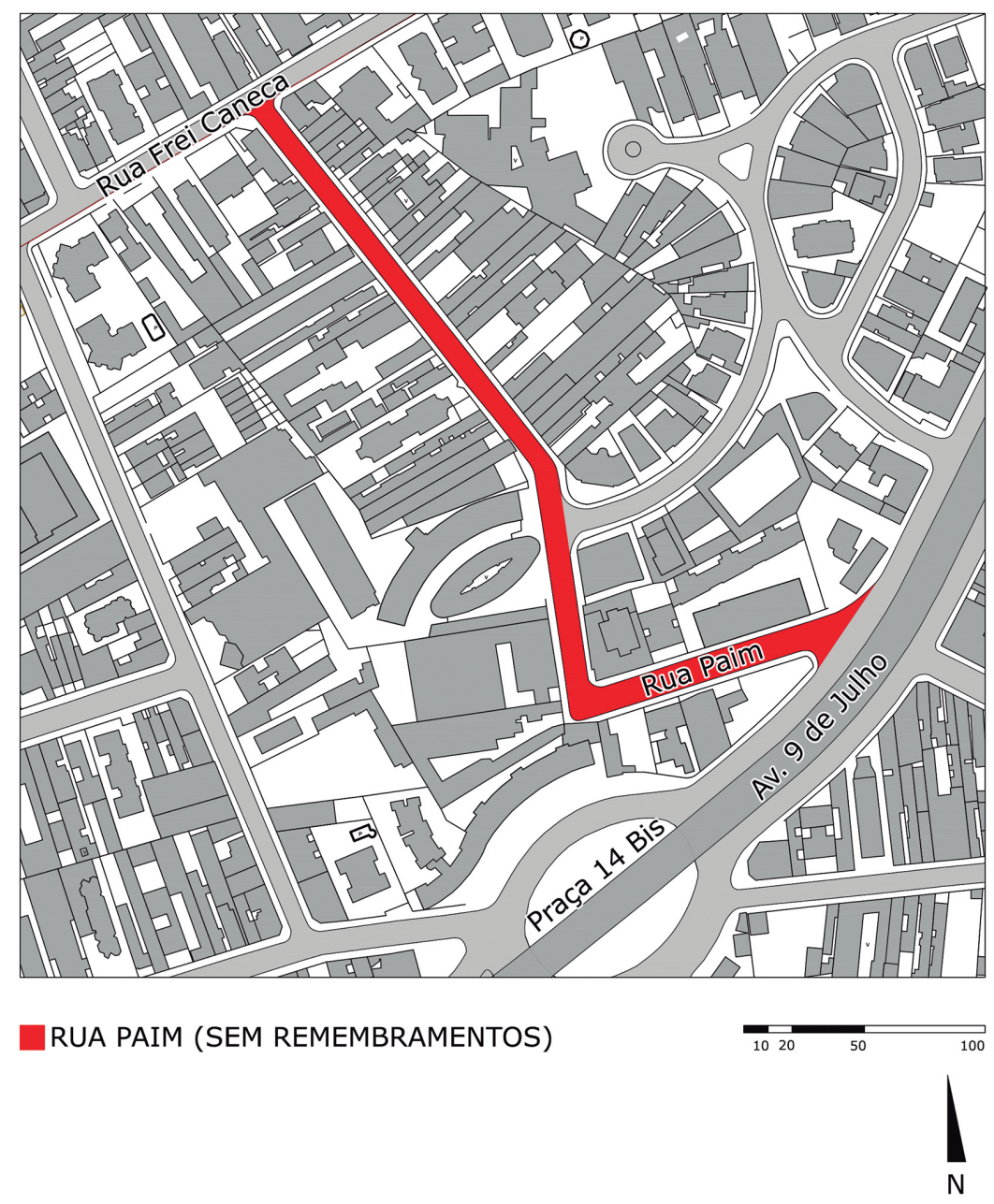

Figura 2 - Mapa cadastral da rua Paim no início dos anos $2000{ }^{5}$

A Paim dos anos 2000 caracterizava-se pelo predomínio de usos mistos (Figura 3), com pequeno comércio e serviços locais. 


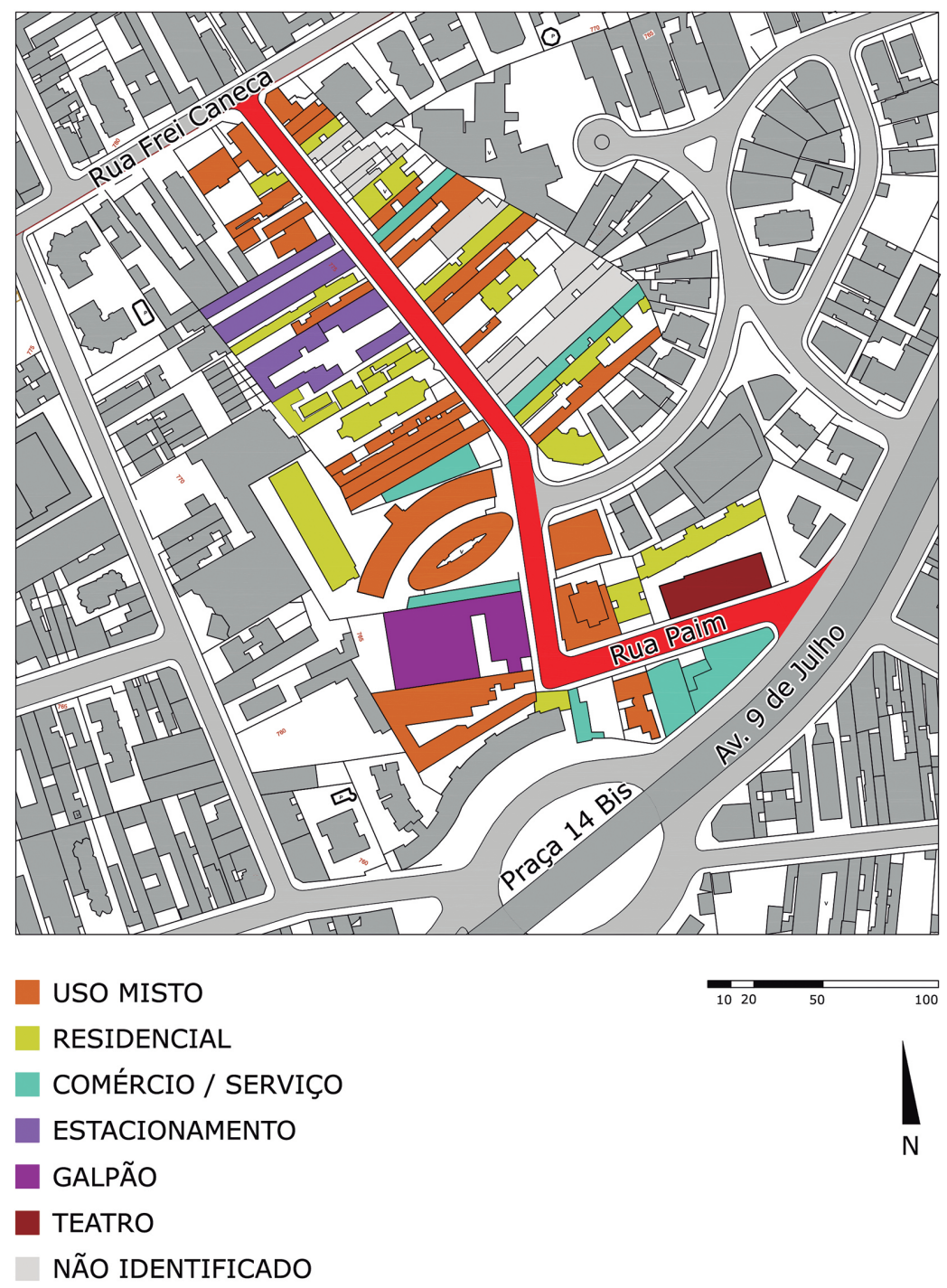

Figura 3 - Mapa de uso e ocupação do solo no início dos anos $2000 .{ }^{6}$

Além do uso misto, outra característica da rua Paim era a predominância de edificações baixas, com no máximo três pavimentos (Figura 4).

Mas o interesse dos investidores na rua Paim não se deu de forma isolada. A inauguração do Shopping Frei Caneca no ano 2001 contribuiu com a paulatina alteração do perfil dos usuários da região, e começou a atrair um público jovem de maior poder aquisitivo interessado em residir próximo à área central, em especial em regiões com intensa diversidade cultural. Aos poucos as atividades mais populares, assim como as populações de menor poder aquisitivo começam a ceder lugar a atividades voltadas a um público de maior renda. 

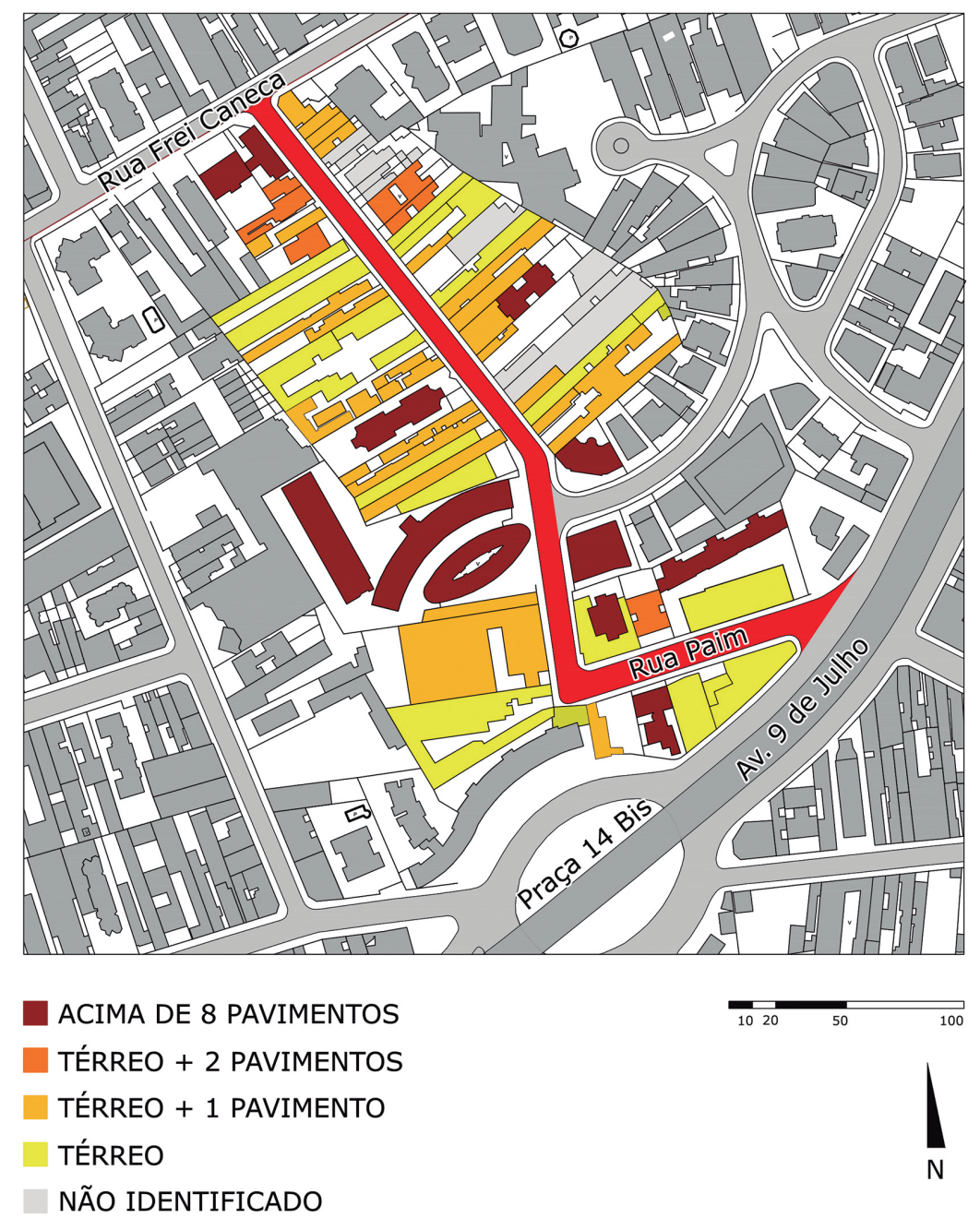

Figura 4 - Gabarito da rua Paim no início dos anos 2000.?

Apesar do casario em precário estado de conservação, da presença de cortiços, da falta de manutenção do espaço público, dos elevados índices de violência urbana, existência de pontos de prostituição e tráfico de drogas, a localização privilegiada colocou a Paim dentro do um contexto de valorização imobiliária de toda a região do Baixo Augusta. Diante da impotência do Estado em diminuir os índices de violência urbana e sem o apoio do poder público em controlar a produção do espaço e proteger as populações de menor poder aquisitivo moradoras do local, criaram-se as condições propícias para a gentrificação da região. A Paim passou a oferecer para o mercado terrenos bem localizados com alto potencial construtivo a preços baixos.

Ao longo dos anos 2000 vários imóveis da Paim foram adquiridos por empreendedores e remembrados, dando início aos processos de aprovação das novas construções. Processos que tiveram no final da década seu auge, com uma sucessão de lançamentos de edifícios que hoje se encontram em construção ou 
já finalizados. O padrão de ocupação do espaço reproduziu as mesmas estratégias de valorização imobiliária via segregação socioespacial que predominou em todo o território ao longo do século anterior na cidade de São Paulo. A diversidade funcional e cultural responsável por atrair o público jovem ao centro da cidade começou aos poucos a ceder lugar a empreendimentos monofuncionais residenciais, isolados da rua, que pretensamente buscam suprir a vida coletiva dos moradores através de uma profusão de serviços e lazer oferecidos dentro do próprio condomínio.

A partir desse momento a Paim passa por um processo de ressignificação e desconstrução não apenas espacial, mas também social. Ao todo, essa reorganização dos lotes deu origem e sete novos empreendimentos residenciais (Figura 5), seis deles já entregues ou em construção.

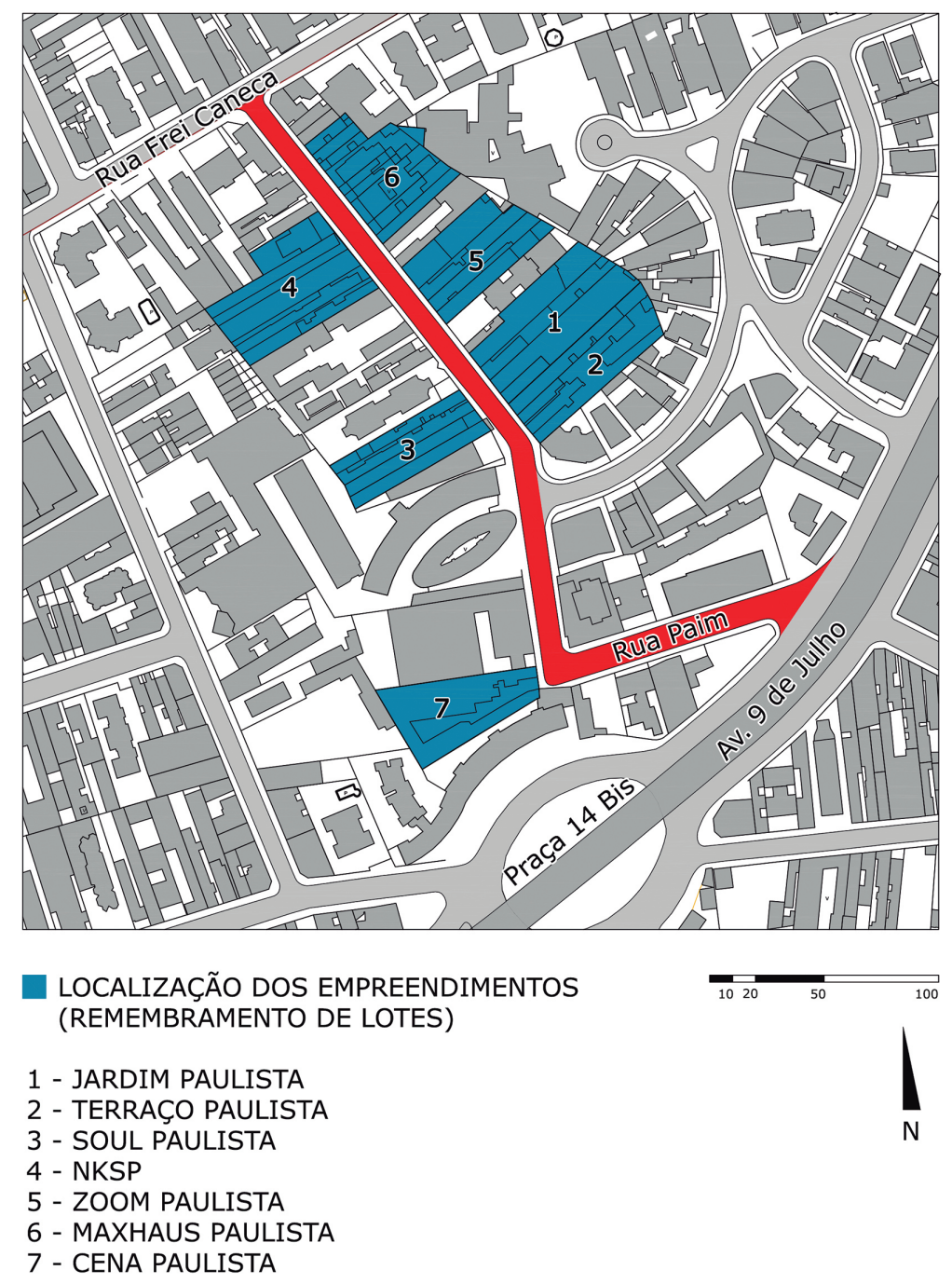

Figura 5 - Remembramento dos lotes da rua Paim e localização dos novos edifícios, segundo ordem de lançamento dos empreedimentos. 
Aspectos como diversidade de classes sociais, multiplicidade de usos e relação de proximidade e permeabilidade com a rua são substituídas por condomínios fechados, voltados à classe média e média alta, isolados no lote, conectados à rua por acessos controlados de pedestres e veículos. Ao invés de incorporar a diversidade de usos e perfis dos moradores como dado de projeto, os novos lançamentos utilizaram a exclusividade e o isolamento (segurança) como estratégias de valorização dos empreendimentos. O resultado foi a substituição da Paim de uso predominantemente misto, por uma "nova" Paim essencialmente residencial (Figura 6) e destinada a um público de maior poder aquisitivo.

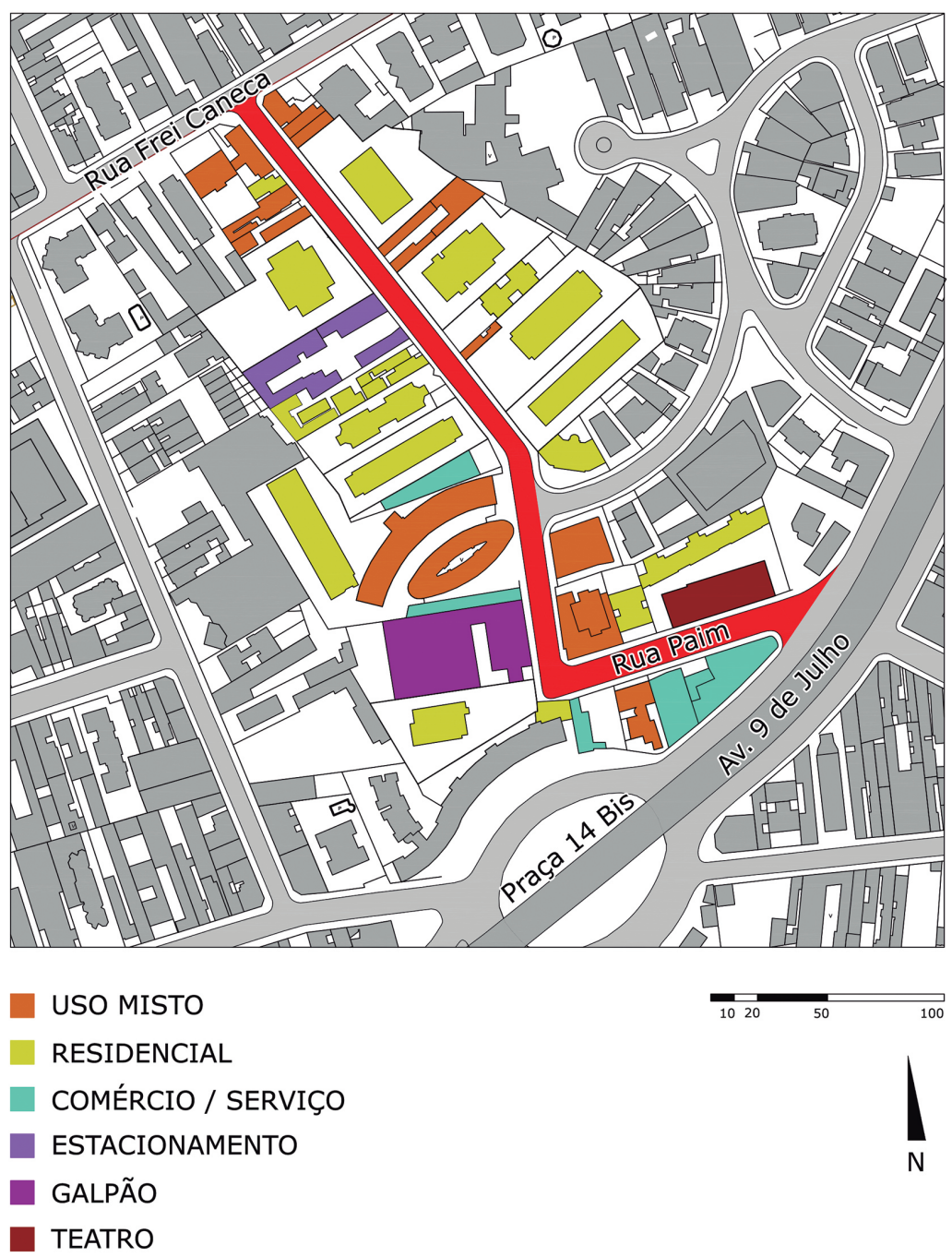

Figura 6 - Mapa de uso e ocupação do solo com inserção dos novos empreendimentos.

Além das alterações de uso, a rua Paim torna-se mais densa e verticalizada, perdendo grande parte de suas características originais (Figura 7). 


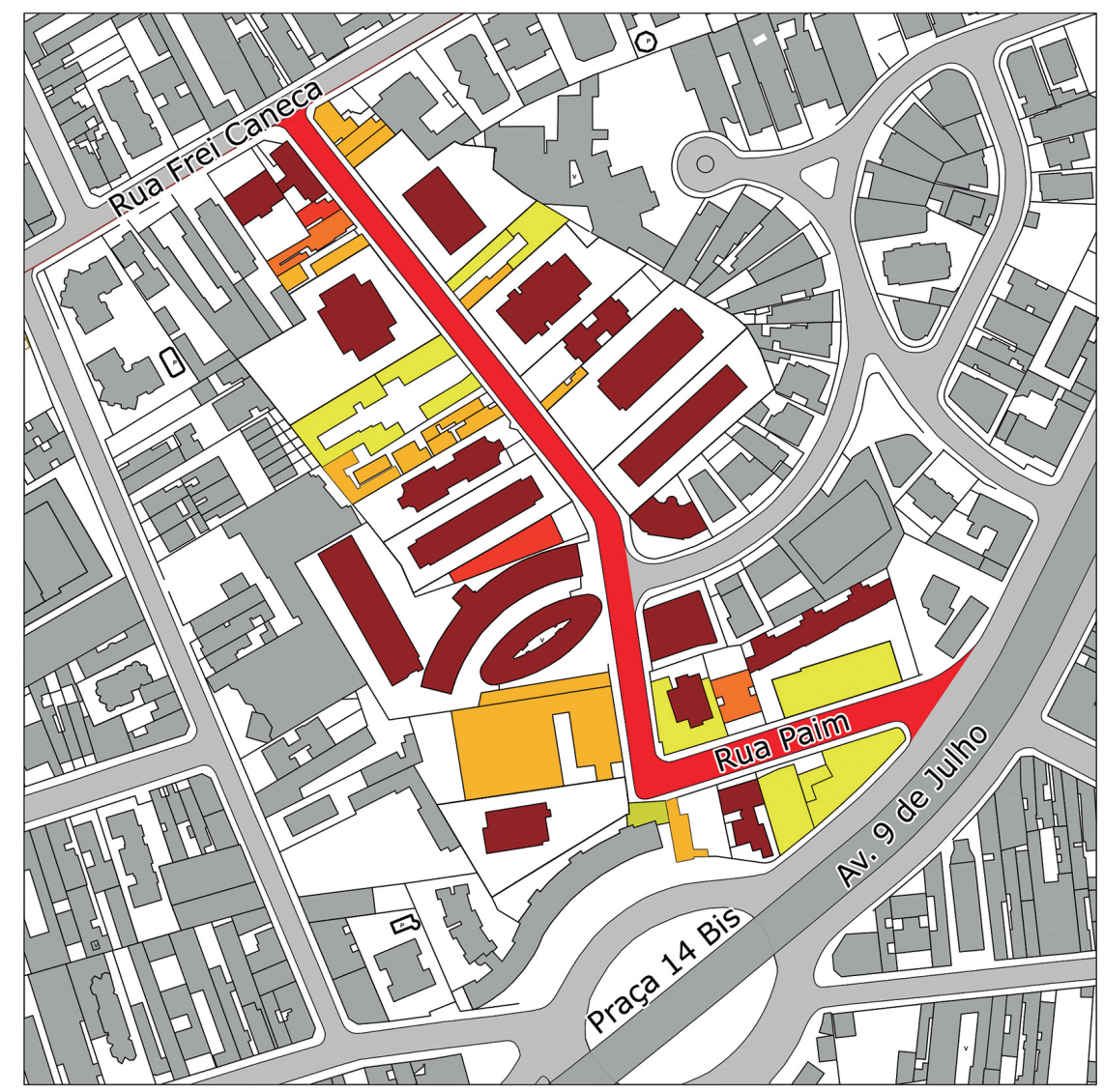

- ACIMA DE 8 PAVIMENTOS

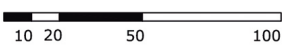

TÉRREO + 3 PAVIMENTOS

TÉRREO + 2 PAVIMENTOS

TÉRREO + 1 PAVIMENTO

TÉRREO

Figura 7 - Gabarito da "Nova” Paim.

\section{Renovação excludente: o perfil da Nova Paim}

Apesar da presença de cortiços e sérios problemas de segurança pública o primeiro empreendimento lançado foi um sucesso de vendas, com todas as 256 unidades vendidas em menos de duas horas. Fato que não só confirmou as expectativas do mercado, mas impulsionou o lançamento dos outros empreendimentos na sequência. Com estratégias de marketing explicitamente voltadas à garantia que os cortiços seriam eliminados, que a rua seria renovada pelo conjunto de novos edifícios e as populações de menor poder aquisitivo deixariam o local, o valor do metro quadrado da Paim chegou quase a triplicar entre o primeiro lançamento (Residencial Jardim Paulista), vendido a cerca de R \$ 4.500,00 o metro quadrado em 2009, e o sexto lançamento (MaxHaus Paulista), que alcançou valores superiores a R\$ 12.000,00 o metro quadrado em 2013. 
Mesmo a presença do Conjunto Santos Dumont, vizinho aos novos empreendimentos e que ao logo das últimas décadas do século XX passou por um processo de abandono similar ao ocorrido nos edifícios São Vito e Mercúrio (hoje demolidos) e ainda hoje abriga populações em situação de vulnerabilidade social, não foi capaz de prejudicar o ritmo acelerado de vendas dos lançamentos. Apesar do precário estado de conservação, o Santos Dumont foi tolerado, tornando-se um resquício da Paim "decadente" de outrora. Em razão da pouca manutenção, da presença de população de menor poder aquisitivo, e de relatos de violência associadas ao cotidiano do Santos Dumont, o conjunto é conhecido por apelidos nada elogiosos, como "favela vertical" e "treme-treme". Ironicamente a valorização da região atingiu o próprio conjunto Santos Dumont, bem como todos os outros imóveis existentes na proximidade, com aumento significativo nos valores de aluguéis e venda de apartamentos.

Embora um dos objetivos iniciais do PDE ao definir e incentivar o adensamento de áreas próximas a corredores de transporte coletivo de massa, tenha sido de aproximar as populações de menor poder aquisitivo das áreas providas de infraestrutura urbana, diminuindo a necessidade de deslocamentos, o público alvo desses empreendimentos foi exatamente o oposto ao pretendido pelo PDE. Além disso grande parte das unidades colocadas à venda foram adquiridas por investidores, e não pelos moradores finais, subvertendo a lógica inicial. Por serem tratadas como mercadorias, grande parte das unidades habitacionais sequer chegaram a ser compradas diretamente pelo consumidor final, fortalendo uma cadeia especulativa em torno desses lançamentos.

Desde o início do processo de transformação, a rua Paim foi vendida como um grande negócio, como uma boa oportunidade para a obtenção de lucros, mas nunca como um exemplo de recuperação de uma região em moldes inclusivos e democráticos. A solução encontrada pelos agentes privados responsáveis pelos novos empreendimentos para a questão da violência urbana, que contribuiu com a degradação do espaço público, foi o isolamento e a guetificação dos novos moradores. Critérios como segurança e proteção foram utilizados como justificativa para as demolições dos cortiços e deslocamento dos antigos moradores. Mas não houve nenhuma preocupação ou ação clara, por parte tanto do poder público como dos agentes privados, com relação ao destino dos antigos moradores. Mais uma vez os problemas urbanos ligados à violência foram simplesmente relocados para outras regiões da cidade ao invés de serem solucionados definitivamente.

Totalizando 1.203 novos apartamentos e 99.414,30 metros quadrados de área total construída, os sete novos edifícios da rua Paim alteraram totalmente a dinâmica do local. Embora os dois primeiros empreendimentos lançados, o Residencial Jardim Paulista e o Residencial Terraço Paulista, tenham sido aprovados na categoria de uso $\mathrm{HMP}^{8}{ }^{8}$ a intensa valorização da região dificultou $\mathrm{o}$ acesso de moradores de menor poder aquisitivo ao local. Fato que comprova a 
distorção entre a teoria (intenções iniciais do PDE, de aproximar os trabalhadores dos meios de transporte de massa, incentivando o adensamento em regiões ricas em infraestrutura) e a prática (valorização imobiliária e elitização de regiões bem localizadas), que culminou no processo de gentrificação da região.

O casario típico da região foi maciçamente substituído e o espaço resultante do novo desenho proposto não manteve nenhum vestígio das relações existentes (relações não apenas espaciais, mas também relações de afetividade e memória coletiva). Embora entre as construções demolidas não houvesse casos de tombamento, e a falta de conservação do casario fosse evidente, havia na rua Paim uma situação urbana e uma diversidade de relações com o espaço público que poderiam ter sido incorporados e até mesmo potencializados como dados de projeto, mas que foram ignorados. O valor histórico do que foi demolido não estava nas construções isoladamente, mas em seu contexto e em sua relação com o espaço público. O resultado das transformações foi uma homogeneização nas relações com o espaço urbano com consequente empobrecimento da diversidade cultural antes existente.

\section{Considerações finais}

O processo de desconstrução espacial da rua, embora intensificado nos anos 2000, teve suas origens nas últimas décadas do século XX, com o paulatino abandono do espaço público e falta de investimentos em manutenção dos edifícios existentes. Apesar do aspecto positivo de atrair novos moradores para a região central da cidade, o processo em sua totalidade apresentou falhas importantes.

Entre essas falhas podem-se ressaltar a inversão de prioridades ao incentivar a construção de novos edifícios antes de estimular efetivamente a recuperação e ocupação de edifícios existentes; o deslocamento dos antigos moradores de menor poder aquisitivo da rua Paim e o processo de gentrificação deflagrado no entorno, com consequente desestruturação das relações sociais existentes; o deslocamento da violência urbana para outras regiões da cidade, uma vez que os problemas referentes a tráfico de drogas e prostituição não foram solucionados, apenas mudaram de "endereço"; a negligência com o espaço existente; a utilização da segregação socioespacial como estratégia de aumento no valor dos imóveis e marketing de vendas explícito; o empobrecimento das relações entre as edificações e o espaço público com consequente perda de diversidade urbana, decorrentes da monofuncionalidade e do isolamento dos novos edifícios no lote; a dificuldade de conter o aumento no valor dos imóveis e de atrair moradores de menor poder aquisitivo, aproximando-os de seus locais de trabalho e finalmente a não avaliação dos impactos do conjunto de empreendimentos na estrutura viária do entorno, em especial sobre a rua Frei Caneca e a avenida 9 de Julho. 
Notas

1 Fonte: Secretaria Municipal de Desenvolvimento Urbano (SMDU). Disponível em: <http://smdu.prefeitura.sp.gov.br/historico_demografico/tabelas/pop_dist.php >. Acesso em: 3 abr. 2014.

2 Fonte: SMDU - Infocidade. Disponível em: <http://infocidade.prefeitura.sp.gov.br/ index.php?cat=7\&titulo=Demografia $>$. Acesso em: 4 abr. 2014.

3 Potential ground renté um dos termos-chave da teoria da gentrificação (Smith, 1979).

4 Montagem sobre foto aérea de 14.12.2008 disponibilizada pelo Google Earth. Disponível em: <https://www.google.com/earth>. Acesso em: 24 set. 2015.

5 Mapa elaborado pela autora a partir de arquivo extensão dxf com divisão cadastral do município, disponibilizado pela SMDU.

6 Mapa elaborado pela autora a partir da observação de imagens disponibilizadas pelo Google Street View de janeiro de 2010, anterior a grande parte das demolições. As edificações com hachura em cinza claro já haviam sido demolidas em 2010 e não puderam ser identificadas. Disponível em: <https://www.google.com.br/maps/>. Acesso em: 15 dez. 2014.

7 Ibidem.

8 Segundo o PDE (Lei n.13.430, de 13 de setembro de 2002), Habitação de Mercado Popular (HMP) é aquela que se destina a famílias de renda igual ou inferior a 16 (dezesseis) salários mínimos ou capacidade de pagamento a ser definida em lei específica, de promoção privada, com padrão de unidade habitacional com até dois sanitários, até uma vaga de garagem e área útil de no máximo $70 \mathrm{~m}^{2}$ (setenta metros quadrados).

\section{Referências}

BONDUKI, N. Imposto progressivo sobre imóveis ociosos. Carta Capital, setembro 2010 .

BONDUKI, N.; KOURY, A. P. Das reformas de base ao BNH: as propostas do Seminário de Habitação e Reforma Urbana. Arquitextos, São Paulo, maio 2010. Disponível em: <http://www.vitruvius.com.br/revistas/read/arquitextos/10.120/3432>. Acesso em: 8 dez. 2014.

CASTRO, C. M. P. D. O centro velho e a moradia: requalificação urbana em São Paulo. In: PLURIUS 2010 - $4^{\circ}$ Congresso Luso Brasileiro para o Planejamento Urbano, Regional, Integrado, Sustentável. Faro/Portugal: Universidade do Algarve, 2010.

FRANCISCO, J. Desconstrução e conhecimento espacial. UFSCAR/Deciv, São Carlos, 2002.

HARVEY, D. A produção capitalista do espaço. São Paulo: Annablume, 2005.

MARICATO, E. O Estatuto da cidade periférica. In: CARVALHO, C. S.; ROSSBACH, A. O Estatuto da Cidade: comentado. São Paulo: Ministério das Cidades: Aliança das Cidades, 2010. p.5-22.

RUIVO, M. P.; CASTRO, C. M. P. D. Dinâmicas socioeconômicas, planejamento e políticas urbanas implementadas na área central de São Paulo nos anos 2000. In: $6^{\circ}$ 
Congresso Luso-brasileiro para o Planejamento Urbano, Regional, Integrado e Sustentável - Pluris, Lisboa, 2014.

SMITH, N. Toward a Theory of Gentrification. A Back to the City Movement by capital, not People. Journal of the American Planning Association, v.45, p.538-48, out. 1979.

YIN, R. K. Estudo de caso: Planejamento e Métodos. Porto Alegre: Bookman, 2001.

RESUMO - Após décadas de abandono e falta de investimentos tanto públicos como privados, a rua Paim, localizada em um importante distrito da área central de São Paulo, passa, ao longo dos anos 2000, por um processo de ressignificação e desconstrução espacial. Apesar de todos os avanços teóricos presentes no Estatuto da Cidade, a aplicação seletiva dos principais instrumentos urbanísticos disponíveis para garantia da função social da propriedade criou condições ideias que fizeram da Paim um grande negócio imobiliário, altamente lucrativo, mas de caráter excludente e gentrificador. O objetivo do trabalho é, pelo exemplo da rua Paim, investigar o processo de produção do espaço urbano no período, como reflexo não apenas do mercado imobiliário, mas também das diretrizes presentes no Plano Diretor Estratégico do município.

PALAVRAS-CHAVE: Desconstrução espacial, Gentrificação, Exclusão social, Mercado imobiliário, Direito à cidade.

ABSTRACT - After decades of neglect and lack of both public and private investments, Paim Street, located in an important central district of São Paulo, underwent a process of re-signification and spatial deconstruction in the first decade of the $21^{\text {st }}$ century. Despite all the theoretical advances achieved by the approval of Federal Law 10.257/01, also known as "Statute of the Cities", the selective application of the main urban instruments available to guarantee the social function of urban property created the ideal conditions to turn Paim Street into a great, highly profitable but exclusionary and gentrifying real estate opportunity. Using the example of Paim Street, this study aims to investigate the production of urban spaces during that time period as a reflection not only of the real estate market, but also of the guidelines defined by the city's Strategic Master Plan.

KEYWORDS: Spatial deconstruction, Gentrification, Social exclusion, Real estate market, Right to the city.

Maria Patricia Ruivo é arquiteta, mestra em Engenharia Urbana pelo Programa de Pós-Graduação em Engenharia Urbana da Universidade Federal de São Carlos (PPGEU-UFSCar). @-patricia_ruivo@uol.com.br.

José Francisco é arquiteto, professor do Programa de Pós Graduação em Engenharia Urbana da Universidade Federal de São Carlos (PPGEU-UFSCar). @ - jfran@ufscar.br I, II Universidade Federal de São Carlos, São Carlos/São Paulo, Brasil.

Recebido em 12.3.2015 e aceito em 7.5.2015. 
